\title{
INTERNAL TREATMENT OF PROCESS WATERS IN PAPER PRODUCTION BY DISSOLVED AIR FLOTATION WITH NEW DEVELOPED CHEMICALS. PART 1: LABORATORY TESTS
}

\author{
Ruben Miranda, Carlos Negro, Angeles Blanco* \\ Department of Chemical Engineering, Faculty of Chemistry, Complutense University of \\ Madrid - Avda. Complutense s/n 28040 Madrid (Spain)
}

\begin{abstract}
New chemicals, based on the synergistic effect between inorganic polyaluminium salts and organic cationic polyelectrolytes, have been tested for the chemical optimization of a dissolved air flotation (DAF) unit, used as internal treatment of process waters in a paper mill based on 100\% recovered paper. Laboratory tests have demonstrated that polyamine modifications of the aluminium salts are the most efficient in the removal of contaminants, being the combination of a polyaluminium nitrate sulphate salt and a polyamine the most efficient. This chemical has been studied under different conditions, such as different dosages or in combination with a flocculant, for the treatment of waters from different paper grade production, and the results have demonstrated a good performance at lab scale. Therefore, a field trial is recommended for assessing its potential benefits at mill scale, which is described in Part II of this work.
\end{abstract}

KEYWORDS: chemical synergistic effects, dissolved air flotation, flocculation, aluminium salts, polyamines, paper recycling.

\section{INTRODUCTION}

Although fresh water consumption has been reduced dramatically during recent decades, the paper industry is still one of the major industrial sectors in terms of water demand. Reduction of water consumption is a key issue nowadays due to more stringent environmental legislation, an increase of water prices, treatment costs, or simply due to lack of water resources $^{1-3}$. As the mill closes the water systems, the reuse of water increases the accumulation of suspended and dissolved and colloidal material (DCM $)^{4-5}$. While suspended solids are removed easily in the existing clarification systems, DCM is almost completely recirculated into the process ${ }^{6-8}$. When present at sufficient concentrations, DCM negatively affects the production process (e.g. blockings, scaling, slime formation, breaks and stickies deposits) $)^{9-11}$ and the quality of the final product (by impairing its physical properties or by the presence of dirt, specks or holes $)^{12-14}$. This is especially important in the production of

\footnotetext{
* To whom correspondence should be addressed. Dpt. Chemical Engineering, Faculty of Chemistry, Complutense University of Madrid. Avda. Complutense s/n E-28040 Madrid (Spain). Phone: +34913944247. Fax: +34913944243. E-mail: ablanco@quim.ucm.es
} 
recycled paper due to the high amount and variety of contaminants introduced in the process $^{15-17}$. Additionally, a growing recycling rate has forced papermakers to process lower quality recovered papers containing a higher level of contamination ${ }^{18-19}$. Therefore, accumulation of DCM is limiting a further closure of the water circuits.

One of the most common internal treatments used in papermaking is dissolved air flotation (DAF), because they treat economically large water flows with a wide range of solids content, between $300 \mathrm{mg} / \mathrm{L}$ and $5000 \mathrm{mg} / \mathrm{L}^{20}$. In recycled paper mills there are up to five DAF units ( $1^{\text {st }}$ loop, $2^{\text {nd }}$ loop, paper machine loop, sludge treatment and effluent treatment $)^{21}$.

In principle, DAF units efficiently remove $80-98 \%$ of suspended solids, e.g. fines and fillers as well as a wide variety of contaminants such as ink particles and lipophilic extractives ${ }^{20,22}$. Besides, with suitable chemicals, finely dispersed and colloidal organic particles $(>0.2 \mu \mathrm{m})$, can also be agglomerated and removed ${ }^{22-25}$. However there is a limit of around $20 \%$ for the reduction of organics, measured as $\mathrm{COD}^{20}$, because the COD load consists mainly of particles smaller than $0.2 \mu \mathrm{m}$ in size ${ }^{25-26}$. According to A.J. Dunham et al. ${ }^{27}, 85 \%$ of the TOC measured in the DCM fraction corresponds to dissolved substances and the remaining $15 \%$ to colloidal substances. Therefore, the destabilisation and removal of DCM is still a bottleneck for papermakers.

A variety of chemicals are used in DAF systems; common chemicals include aluminium sulphate, ferric chloride, aluminium-based products such as polyaluminium chloride, aluminium chlorhidrate polyaluminium sulphate, minerals such as bentonites or talcs, organic polymers such as polyacrylamides (PAMs), poly(diallyldimethylammonium chloride), polyamines, polyvinyl amides, etc. ${ }^{28-31}$. Nowadays, there is a great interest in the chemical optimization of DAF by the development of tailor-made chemicals ${ }^{32}$. In this sense, conventional chemicals can be modified by the optimization of their properties such as the molecular weight and the charge density in the case of organic polymers ${ }^{33}$, or the basicity, strength or the presence of small amounts of other substances such as sulphate, silica and calcium in the case of aluminium-based products ${ }^{34}$. On the other hand, the synergy between inorganic and organic chemicals is currently of growing interest. This synergy can be obtained by two different approaches: first, using two components, or even three or more ${ }^{35-38}$, which are added separately to the waters, and second, using a single chemical based on both inorganic and organic constituents. For example, the surface modification of bentonites with cationic surfactants such as quaternary ammonium compounds ${ }^{39}$ or the modification of different aluminium compounds with polysilicic acid ${ }^{40}$. This second approach is the one followed in this study, in which different aluminium salts have been combined with cationic organic polymers.

On one side, aluminium-based products have the advantage that $\mathrm{Al}^{3+}$ ion catches DCM better than other treatments used widely in DAFs at deinking mills, e.g. bentonite/PAM chemistry $^{38}$. On the other side, cationic polymers enhance the coagulation of negatively charged particles by charge neutralization/precipitation mechanisms ${ }^{41}$, improving the removal of DCM, because of its anionic charge ${ }^{28}$. Although more expensive than its inorganic 
counterpart, organic coagulants typically offer the advantage of lower dosages, broader $\mathrm{pH}$ operating range and smaller sludge production ${ }^{41}$.

The new chemicals have been tested at lab scale and the most efficient product has been evaluated at mill scale. Finally, single and dual systems have been compared to determine the most efficient product.

\section{MATERIALS AND METHODS}

\subsection{Water samples}

The study was carried out in a Spanish paper mill using $100 \%$ recovered paper as raw material. The mill manufactures both newsprint and light weight coated (LWC) paper. Water samples used in this study were taken from the inlet to the DAF unit located in the second loop of the deinking line, which treats the clear filtrate from a disc filter. A further description of the deinking line is shown in Part II of this work, dealing with field trials carried out in this DAF unit.

Different types of process waters, from newsprint and LWC paper production, were used in the present study. Q1 waters were used for the determination of the most efficient chemical for the removal of DCM in newsprint process waters. Q2 and Q3 waters were used for a detailed study of the most efficient chemical: Q2 for the study of an extensive range of dosages and Q3 for the evaluation of its possible combination with a flocculant (dual system). Additional tests with Q4 waters were carried out for determining the behaviour of the chemical in waters from LWC paper production. The contamination load of the different water samples are presented in the Results and Discussion section.

\subsection{Chemicals}

Chemicals used in this study have been supplied by Sachtleben Chemie GmbH. These chemicals are new products, obtained by direct blending of commercial polyaluminium salts and cationic polyelectrolytes. The polyaluminium salts used are polyaluminium chloride (PAC), polyaluminium chloride sulphate (PACS) and polyaluminium nitrate sulphate (PANS), whose properties are summarized in Table 1. These salts have been modified by adding different dosages, from $0.6 \%$ to $2.4 \%$, of three cationic polyelectrolytes: a polyacrilamide (PAM), a polyvinylamide (PVA) and a polyamine (PA) with charge densities of $12 \%, 12 \%$ and $17 \%$, respectively. Not every polyaluminium salt/polyelectrolyte mixture is possible due to their low stability. A total of 13 chemical treatments have been tested: the 3 polyaluminium salts of base (PAC, PACS and PANS) and 10 modifications of these aluminium salts (2 modifications for PAC, 4 modifications for PACS and other 4 for PANS). The active content, defined as the dosage of organic polymer added to the aluminium salt, the concentration of aluminium and the dry content of the final products are summarized in Table 2. 
Table 1. Properties of the polyaluminium salts.

\begin{tabular}{|l|c|c|c|c|c|c|c|c|c|c|}
\hline \multicolumn{1}{|c|}{ Chemical } & $\begin{array}{c}\mathbf{A l} \\
\text { (\%) }\end{array}$ & $\begin{array}{c}\mathbf{C l} \\
\text { (\%) }\end{array}$ & $\begin{array}{c}\mathbf{S O}_{\mathbf{4}} \\
\text { (\%) }\end{array}$ & $\begin{array}{c}\mathbf{N O}_{3} \\
\text { (\%) }\end{array}$ & $\mathbf{C l} / \mathbf{A l}$ & $\mathbf{O H}$ & $\mathbf{p H}$ & Monomeric & Oligomeric & Polymeric \\
\hline PAC - $\mathrm{Al}_{\mathrm{n}}(\mathrm{OH})_{\mathrm{x}}(\mathrm{Cl})_{\mathrm{y}}$ & 8.9 & 22 & 0 & 0 & 2.5 & 37 & $<1$ & 20 & 70 & 10 \\
\hline $\begin{array}{l}\text { PACS - } \\
\mathrm{Al}_{\mathrm{n}}(\mathrm{OH})_{\mathrm{x}}(\mathrm{Cl})_{\mathrm{y}}\left(\mathrm{SO}_{4}\right)_{\mathrm{z}}\end{array}$ & 5.4 & 9.3 & 3 & 0 & 1.7 & 46 & 2.7 & 15 & 45 & 40 \\
\hline $\begin{array}{l}\text { PANS - } \\
\mathrm{Al}_{\mathrm{n}}(\mathrm{OH})_{\mathrm{x}}\left(\mathrm{NO}_{3}\right)_{\mathrm{y}}\left(\mathrm{SO}_{4}\right)_{\mathrm{z}}\end{array}$ & 5.4 & - & 3 & 15 & 0 & 46 & 2.5 & 22 & 35 & 43 \\
\hline
\end{tabular}

Table 2. Properties of the chemicals tested.

\begin{tabular}{|c|c|c|c|c|}
\hline Chemical family & Chemical & $\begin{array}{c}\text { Active } \\
\text { content (\%) }\end{array}$ & $\begin{array}{l}\mathrm{Al}^{3+} \\
(\%)\end{array}$ & Dry content (\%) \\
\hline \multirow{3}{*}{$\begin{array}{c}\text { PAC family } \\
\text { (polyaluminium chloride) }\end{array}$} & PAC & - & 8.9 & 34.1 \\
\hline & PAC-PAM & 1.5 & 7.8 & 33.9 \\
\hline & PAC-PVA & 1.5 & 7.8 & 33.9 \\
\hline \multirow{5}{*}{$\begin{array}{l}\text { PACS family } \\
\text { (polyaluminium chloride } \\
\text { sulphate) }\end{array}$} & PACS & - & 5.4 & 21.7 \\
\hline & PACS-PAM1 & 0.6 & 5.1 & 21.3 \\
\hline & PACS-PAM2 & 2.4 & 4.3 & 19.9 \\
\hline & PACS-PVA & 0.6 & 5.1 & 21.3 \\
\hline & PACS-PA & 1.8 & 3.2 & 20.4 \\
\hline \multirow{5}{*}{$\begin{array}{c}\text { PANS family } \\
\text { (polyaluminium nitrate } \\
\text { sulphate) }\end{array}$} & PANS & - & 5.2 & 21.7 \\
\hline & PANS-PAM1 & 0.6 & 5.1 & 21.3 \\
\hline & PANS-PAM2 & 1.2 & 4.8 & 20.9 \\
\hline & PANS-PVA & 1.2 & 4.8 & 20.9 \\
\hline & PANS-PA & 1.8 & 3.2 & 20.4 \\
\hline
\end{tabular}

Note: PAM indicates polyacrylamide; PVA indicates polyvinylamide; PA indicates polyamine.

\subsection{Methodology}

Figure 1 summarizes the method used to evaluate the efficiency of the chemicals at labscale. DAF tests were carried out in a lab-cell, model Flottatest FTH3, supplied by Orchidis 
Laboratoires. In these tests, different dosages of chemicals were added from 1.0 wt.\% stock solutions to a 1-L volume of sample. After 5 minutes of mixing at $180 \mathrm{rpm}, 200 \mathrm{~mL}$ tap water saturated with air at about 6.5 bar was added for the flotation. Ten minutes after the addition of the saturated water, a sample of the clarified was collected (around $250 \mathrm{~mL}$ ). A blank was carried out without the addition of any chemical, to consider the dilution of the samples and the efficiency of the DAF itself; this reference sample is named REF. The tests were carried out in duplicate and the average error between replicates was always lower than $5 \%$. All of the tests were carried out at room temperature.

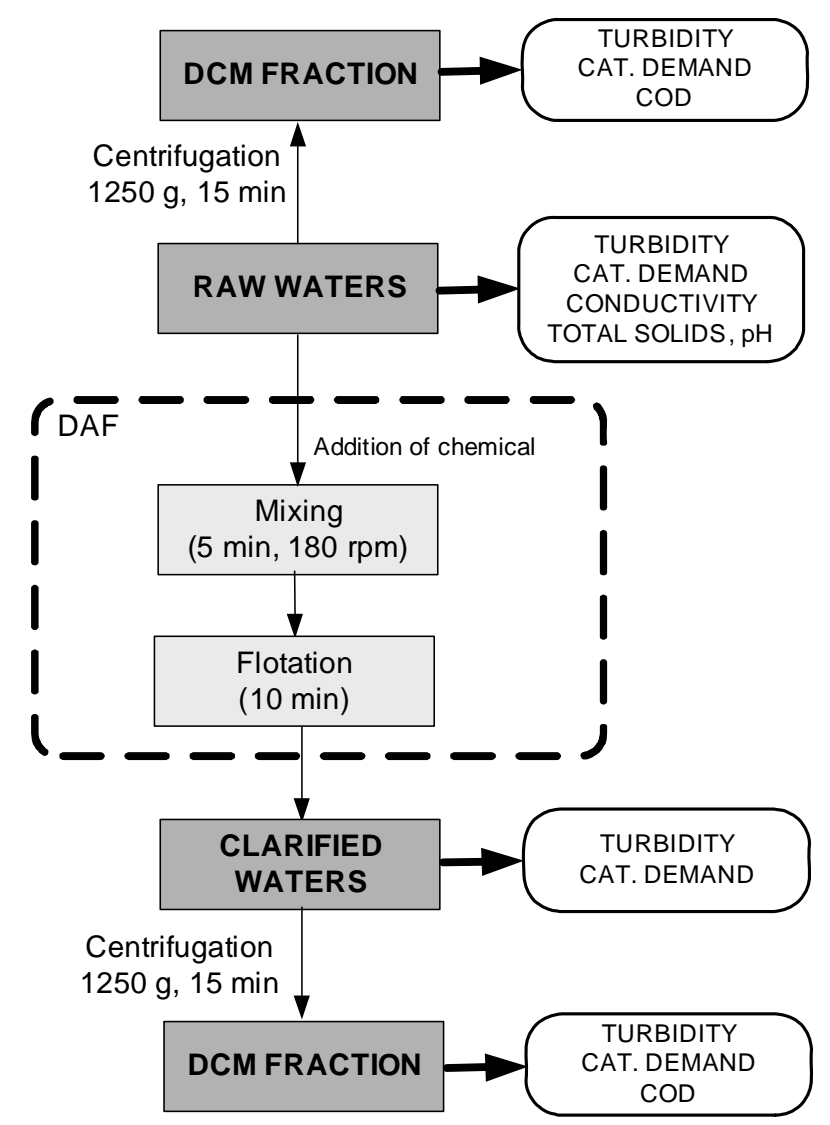

Figure 1. Protocol for determining the chemical efficiency of the different treatments at lab scale.

Focused beam reflectance measurement (FBRM) has been used for determining the optimal dosage of the different products. FBRM is a well-known technique for optimizing flocculation $^{30-31,42-43}$. Chemicals were added from a $1.0 \mathrm{wt} \%$ solution at a constant rate of 0.5 mL every $30 \mathrm{~s}$, by an automatic titrator (Compact I, Crison Instruments S.A.), to $100 \mathrm{~mL}$ of sample. The evolution of the mean chord size distribution (a measure of the floc size) was recorded as a function of the chemical dosage added. At low dosages of the chemicals, the mean chord size rises approximately linearly with the polymer addition. At higher dosages, the addition of a higher dosage of chemical does not significantly increase the mean chord size, remaining approximately constant or even decreasing. The intersection of the two lines which represent these two trends is considered the optimal dosage of the polymer ${ }^{43}$. Higher dosages do not produce any further increase in the flocs size ${ }^{44}$. 
Isolation of the DCM was carried out by centrifugation at $1250 \mathrm{~g}$ during 15 minutes in a Universal 16 centrifuge (Hettich Zentrifugen $\mathrm{GmbH}$ ). Samples before and after centrifugation were characterized.

Turbidity was measured with a LP 2000-11 nephelometer supplied by Hanna Instruments, according to ISO 7027:2001. Cationic demand was measured by colloidal titration of the samples with $0.001 \mathrm{~N}$ poly-diallyldimethylammonium chloride (PDADMAC). The end point was detected with a PCD 03 Particle Charge Detector (Mütek Analytic GmbH) used in combination with an automatic titrator, model Compact Titrator I (Crison Instruments, S.A). The COD of samples was measured employing the NANOCOLOR ${ }^{\circledR}$ COD 1500 test method (Macherey-Nagel GmbH \& Co) with PF-11 Filterphotomether (Macherey-Nagel GmbH \& Co) according to ISO 15705:2002. The total solids content was determined according to Method $2450 \mathrm{~B}^{45}$. Conductivity was measured with a model 524 conductimeter (Crison Instruments, S.A.), according to the ISO 7888:1985 method. The $\mathrm{pH}$ was measured using a model $507 \mathrm{pH}$ meter (Crison Instruments), according to Method 4500- $\mathrm{H}^{+}$-B-Electrometric ${ }^{45}$.

Once the best treatment was selected, a detailed study was carried out for newsprint and LWC paper production. First, an extensive range of dosages were tested in order to select the optimal dosage recommended for the field trials. Second, the convenience of using a conventional flocculant in conjunction with the selected product was also evaluated. Both studies were carried out with waters from newsprint. Third, the efficiency of this product to treat waters from LWC paper production was also evaluated.

\section{RESULTS AND DISCUSSION}

\subsection{Tests for selecting the most efficient chemical}

First, the chemicals were tested at the optimal dosage determined by FBRM. As the dosages were very different (from 220 to $2000 \mathrm{mg} / \mathrm{L}$ ), a second set of tests were carried out at similar dosages of all the products $(700-800 \mathrm{mg} / \mathrm{L})$, in order to confirm results obtained previously. All of the tests were carried out with the same raw waters from newsprint production (Q1 waters), whose contamination load is summarized in Table 3. 
Table 3. Characterisation of waters used for selecting the most efficient chemical (Q1 waters).

\begin{tabular}{|c|c|c|c|c|c|c|c|c|}
\hline $\begin{array}{c}\text { Sample } \\
\text { symbol }\end{array}$ & $\begin{array}{c}\text { Paper } \\
\text { grade }\end{array}$ & $\begin{array}{c}\text { Water } \\
\text { type }\end{array}$ & $\mathbf{p H}$ & $\begin{array}{c}\text { Cond. 25 } \mathbf{~}^{\mathbf{C}} \\
\mathbf{( m S / \mathbf { c m } )}\end{array}$ & $\begin{array}{c}\text { Total } \\
\text { solids } \\
\text { (g/L) }\end{array}$ & $\begin{array}{c}\text { Turbidity } \\
\text { (NTU) }\end{array}$ & $\begin{array}{c}\text { CD } \\
\text { (meq/L) }\end{array}$ & $\begin{array}{c}\text { COD } \\
\text { (ppm) }\end{array}$ \\
\hline Q1 & Newsprint & $\begin{array}{c}\text { Raw } \\
\text { waters }\end{array}$ & 7.5 & 2.70 & 4.20 & 1080 & 0.77 & - \\
\cline { 2 - 8 } & $\begin{array}{c}\text { DCM } \\
\text { fraction }\end{array}$ & 7.5 & 2.68 & - & 90 & 0.78 & 1860 \\
\hline
\end{tabular}

\subsubsection{Efficiency of the chemicals at the optimal dosage}

First, the optimal dosage for each of the chemicals was determined by FBRM. Table 4 summarizes the optimal dosage for each chemical and the relative reduction of the optimal dosage compared to the base aluminium salt.

Table 4. Optimal dosages of the chemicals determined by FBRM technique.

\begin{tabular}{|c|c|c|c|c|c|c|c|c|}
\hline \multicolumn{3}{|c|}{ PAC family } & \multicolumn{3}{c|}{ PACS family } & \multicolumn{3}{c|}{ PANS family } \\
\hline Chemical & O.D.* & $\begin{array}{c}\% \\
\text { Red.** }\end{array}$ & Chemical & O.D.* & $\%$ Red.** & Chemical & O.D.* & $\begin{array}{c}\% \\
\text { Red.** }\end{array}$ \\
\hline PAC & 800 & - & PACS & 1700 & - & PANS & 2000 & - \\
\hline PAC-PAM & 220 & 72.5 & PACS-PAM1 & 800 & 52.9 & PANS-PAM1 & 700 & 65.0 \\
\hline PAC-PVA & 960 & -20.0 & PACS-PAM2 & 400 & 76.5 & PANS-PAM2 & 550 & 72.5 \\
\hline \multicolumn{2}{|}{} & PACS-PVA & 1700 & 0.0 & PANS-PVA & 1400 & 30.0 \\
\cline { 3 - 9 } & PACS-PA & 800 & 52.9 & PANS-PA & 700 & 65.0 \\
\hline
\end{tabular}

* O.D. means optimal dosage (mg/L)

** \% Red. means the reduction percentage of the optimal dosage of the chemical respect to the base aluminium salt.

Polyacrylamide and polyamine modifications are the most efficient. Polyacrylamide modifications of the aluminium salts caused a reduction, on average, of $68 \%$ of the optimal dosage required by the base aluminium salts while polyamine modifications caused an average reduction of 59\%. On the contrary, polyvinylamide modifications had no significant influence: one product is better than the base aluminium salt used for reference (PANS-PVA), while another is worse (PAC-PVA) and the third has the same optimal dosage (PACS-PVA). 
Figures 2 and 3 summarize the efficiency of the chemicals at lab-scale DAF in terms of reduction of turbidity, cationic demand and COD of the samples. Both the turbidity and the cationic demand are greatly reduced by the use of the chemicals. The best reduction in turbidity obtained was $90-95 \%$ before centrifugation and $75-80 \%$ after centrifugation, and the highest reduction of cationic demand was close to $80 \%$, both before and after centrifugation. The reduction of COD in centrifuged samples is minor, close to $20 \%$. All these reductions are referred to as REF values.

In the family of PACs, similar results have been obtained with the aluminium salt of base (PAC) and with its polyacrylamide modification, despite the very different dosages used: 800 $\mathrm{mg} / \mathrm{L}$ in the case of PAC and $220 \mathrm{mg} / \mathrm{L}$ in the case of PAC-PAM. The other chemical in the family, PAC-PVA, reduced the contamination load of the waters to a lower extent than the base product, although its dosage was $20 \%$ higher. In the PACS family, the best results are obtained with the aluminium salt of base (PACS) and with the modifications PACS-PA and PACS-PVA. It is important to notice than PACS-PA obtained similar results than PACS and PACS-PVA but at half the dosage $(800 \mathrm{mg} / \mathrm{L}$ versus $1700 \mathrm{mg} / \mathrm{L})$. Polyacrylamide modifications, at dosages of $400 \mathrm{mg} / \mathrm{L}$ and $800 \mathrm{mg} / \mathrm{L}$, obtained similar results, and were clearly less valuable than polyamine modification. In the family of PANS, the best products are the base aluminium salt and PANS-PA as occurs with the PACS family. They obtained similar results but the dosage of PANS-PA was nearly a third of that used with PANS (700 $\mathrm{mg} / \mathrm{L}$ versus $2000 \mathrm{mg} / \mathrm{L}$ ). The polyacrylamide modifications tested gave worse results than PANS-PA although dosages tested were very similar to that of PANS-PA (700 mg/L PANSPAM1 and $550 \mathrm{mg} / \mathrm{L}$ PANS-PAM2).

According to these results, polyamine modification is promising. Polyamine modified chemicals are clearly the most efficient in removing turbidity and cationic demand. However, second best modifications, based on polyacrylamide, were tested at lower dosages $(500 \mathrm{mg} / \mathrm{L}$ versus $750 \mathrm{mg} / \mathrm{L}$, average values). In the removal of COD, both polyacrylamide and polyamine modifications showed a very similar efficiency. Active contents used in polyamine modifications have always been higher than polyacrylamide and polyvinylamide modifications: 1.8 wt.\% versus 1.26 wt.\% (PAM modifications) and 1.10 wt.\% (PVA modifications). This could be a reason for the higher efficiency of polyamine-based chemicals. Since the optimal dosages were very different for the different chemicals, varying from 220 to $2000 \mathrm{mg} / \mathrm{L}$, new tests were carried out in which the products were tested at about the same dosages $(700 \mathrm{mg} / \mathrm{L}$ for chemicals based on PAC and PACS and $800 \mathrm{mg} / \mathrm{L}$ for chemicals based on PANS). 

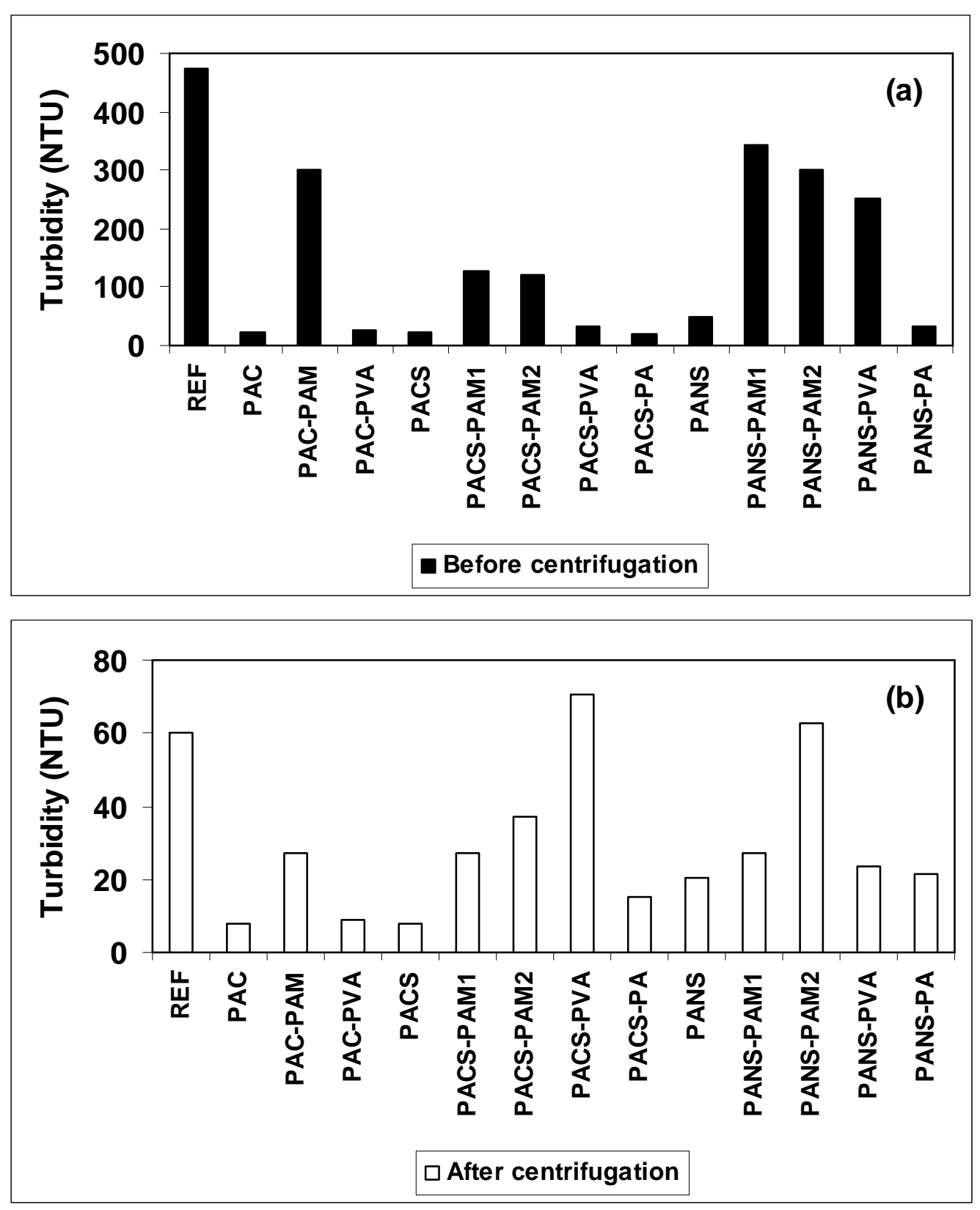

Figure 2. Efficiency of the chemicals at the optimal dosage on turbidity: (a) before centrifugation and (b) after centrifugation. 

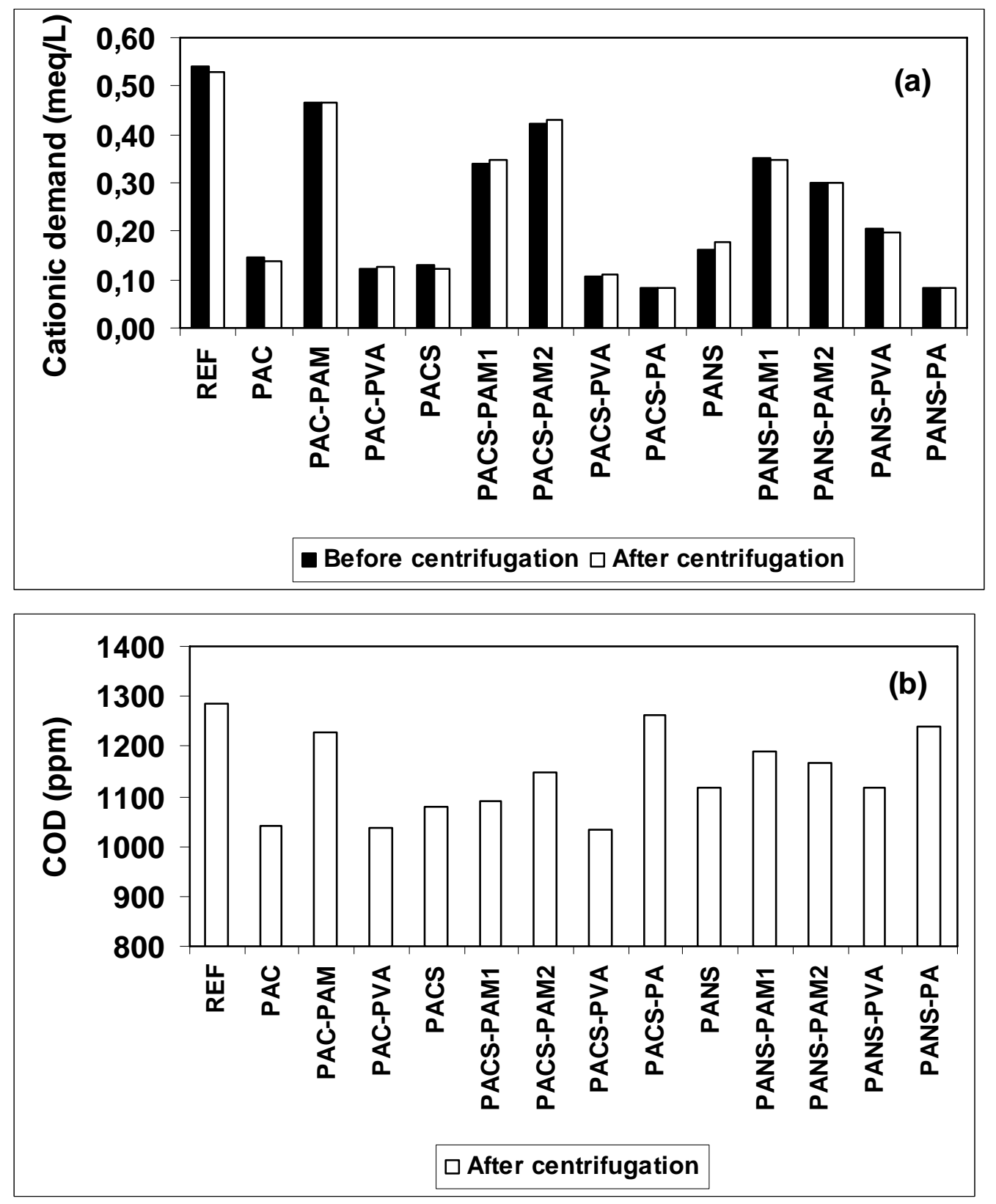

Figure 3. Efficiency of the chemicals at the optimal dosage on: (a) cationic demand and (b) COD.

\subsubsection{Efficiency of aluminium salts at similar dosages $(700-800 \mathrm{mg} / \mathrm{L})$}

For confirming the observations found in the DAF tests at the optimal dosages of the chemicals, additional tests were carried out with the same waters to compare the efficiency of the different chemicals at similar dosages. The results of turbidity, cationic demand and COD are summarized in Figure 4 and 5. 


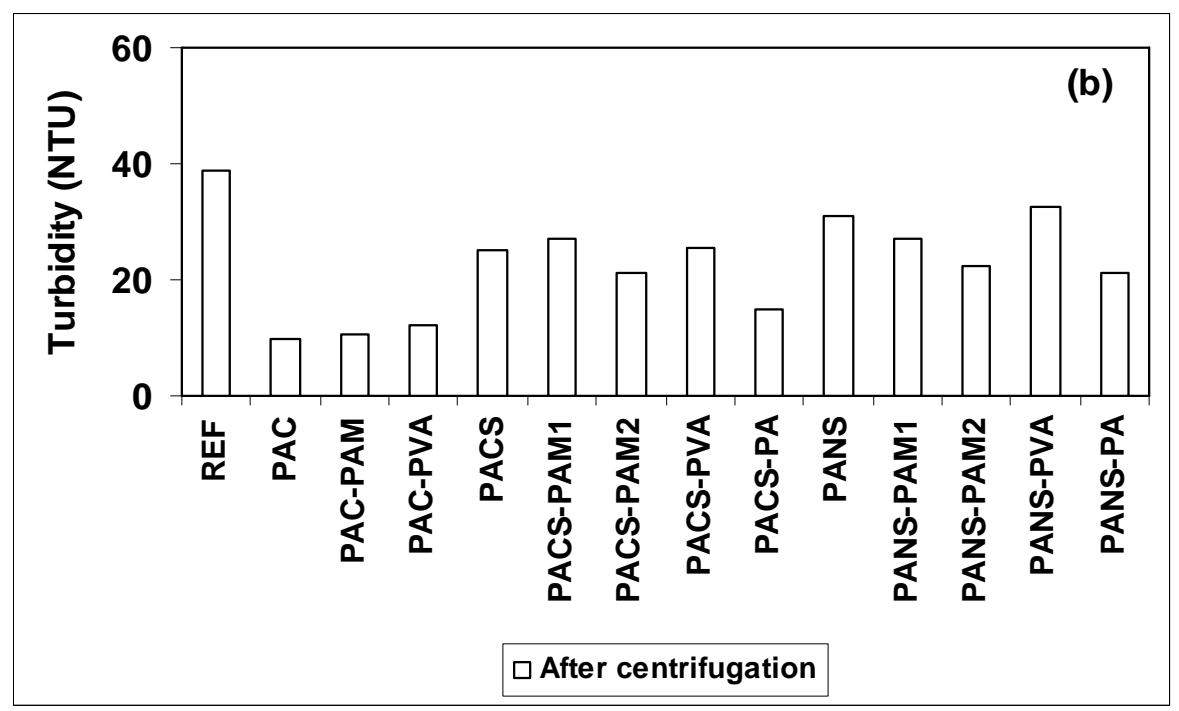

Figure 4. Efficiency of the chemicals at similar dosages (700-800 mg/L) on turbidity: (a) before centrifugation and (b) after centrifugation.
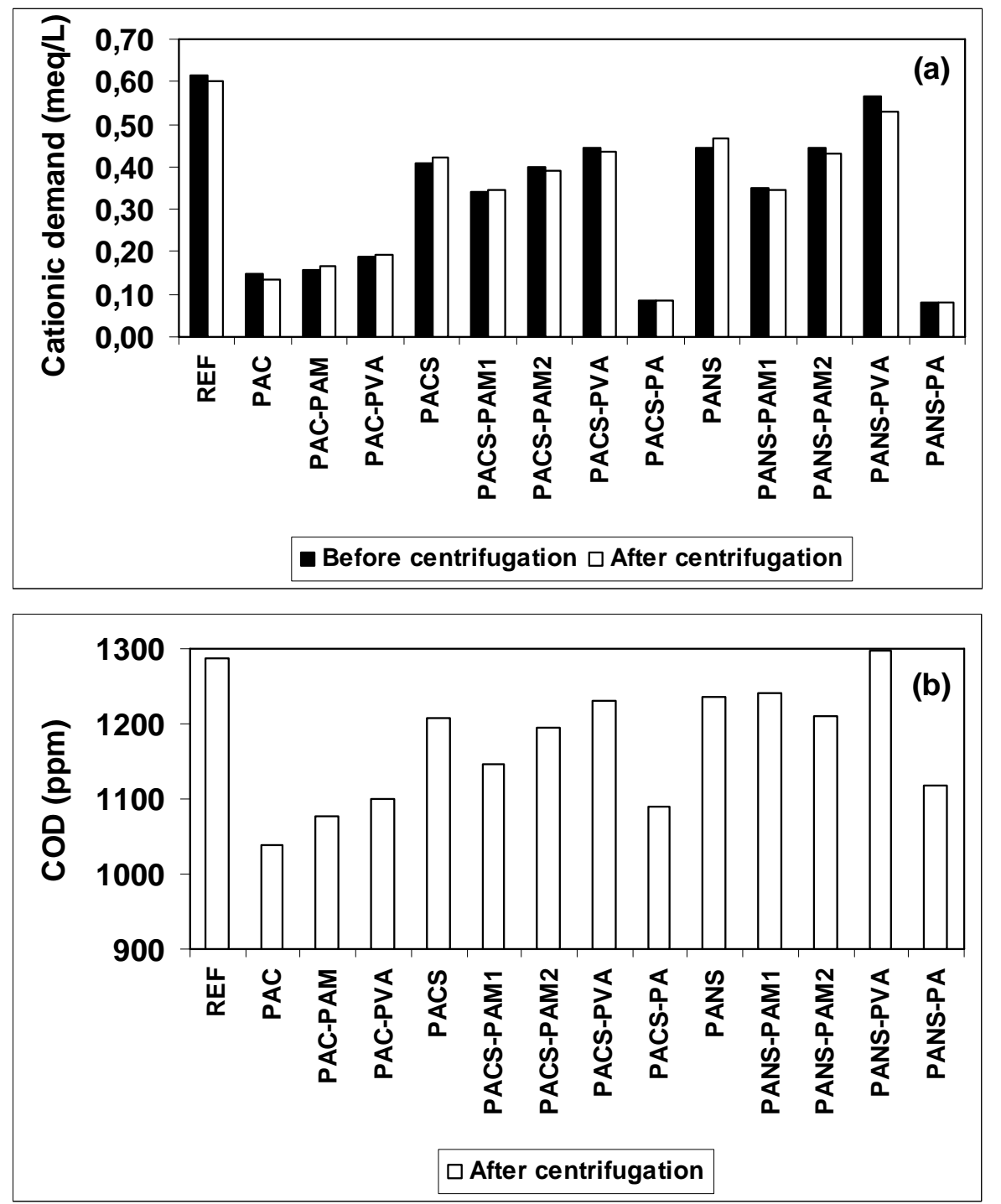

Figure 5. Efficiency of the chemicals at similar dosages $(700-800 \mathrm{mg} / \mathrm{L})$ on: (a) cationic demand and (b) COD. 
Chemicals of the PAC family and their polyamine modifications (PACS-PA and PANS-PA) demonstrated to be the most efficient products for reducing turbidity: around $90 \%$ before centrifugation and 50-70\% after centrifugation. Residual levels of turbidity obtained were as low as 20-30 NTU. Considering the reduction of cationic demand, polyamine modifications were more efficient than PAC products, obtaining an $87 \%$ removal versus an average $73 \%$ removal with products of the PAC family. In the case of COD, the most efficient products are the PAC family and polyamine modifications, with COD reductions in the $15-20 \%$ range.

Polyamine modifications were selected as the most efficient products considering the major difference between the efficiency of polyamine modifications and PAC products on the cationic demand. PANS-PA was selected instead of PACS-PA because PANS-PA obtained exactly the same results as than PACS-PA but at a lower dosage: $700 \mathrm{mg} / \mathrm{L}$ versus $800 \mathrm{mg} / \mathrm{L}$. Besides, some further tests with waters with a higher contamination load (LWC paper production) confirmed that PAC has a lower efficiency than PACS-PA and PANS-PA. Dosages of $250 \mathrm{mg} / \mathrm{L}$ of PACS-PA and PANS-PA were able to reduce turbidity from 10,100 NTU (reference) to $210-230 \mathrm{NTU}$, while dosages as high as $1000 \mathrm{mg} / \mathrm{L}$ only reduced turbidity to 590 NTU (data not shown).

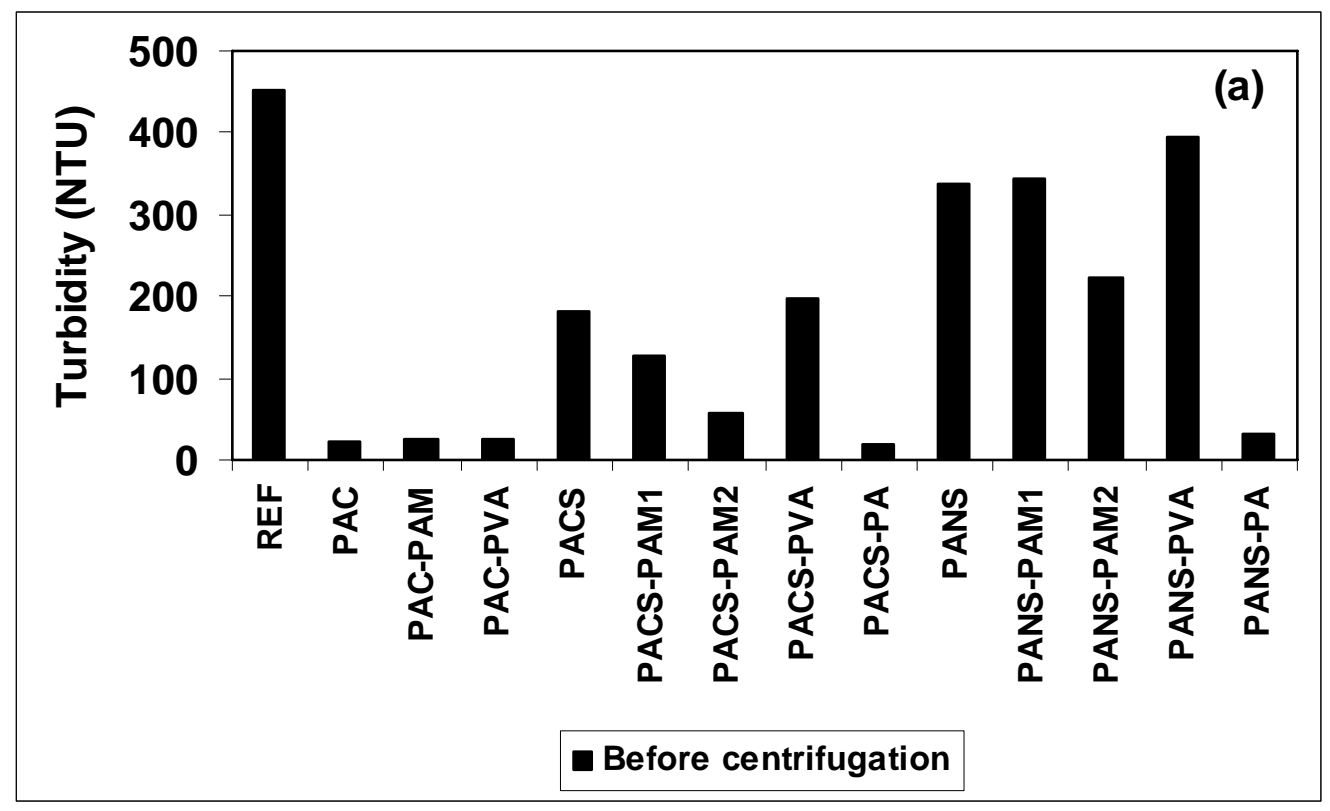

\subsection{Preliminary tests for industrial trials}

Preliminary tests for industrial trials were carried out with different types of waters, from newsprint and LWC paper production, in order to evaluate the efficiency of PANS-PA under different conditions. First, the effect of different dosages on the removal efficiency of contaminants was determined. Second, the potential benefits of using PANS-PA in combination with a flocculant (dual systems) were assessed and its efficiency was compared to a reference product (the coagulant currently used in the paper mill). Both studies were carried out with waters from newsprint production. The third study is related to the efficiency of PANS-PA for treating waters with a high contamination load, in other words waters from 
LWC paper production. The contamination load of the different waters used in these tests is summarized in Table 5.

Table 5. Characterisation of waters used in the preliminary tests for industrial trials (Q2, Q3 and Q4).

\begin{tabular}{|c|c|c|c|c|c|c|c|c|}
\hline $\begin{array}{l}\text { Sample } \\
\text { symbol }\end{array}$ & $\begin{array}{l}\text { Paper } \\
\text { grade }\end{array}$ & $\begin{array}{c}\text { Water } \\
\text { type }\end{array}$ & pH & $\begin{array}{c}\text { Cond. } 25 \\
{ }^{\circ} \mathrm{C} \\
\text { (mS/cm) }\end{array}$ & $\begin{array}{c}\begin{array}{c}\text { Total } \\
\text { solids } \\
(\mathrm{g} / \mathrm{L})\end{array} \\
\end{array}$ & $\begin{array}{c}\text { Turbidity } \\
\text { (NTU) }\end{array}$ & $\begin{array}{c}\text { CD } \\
(\mathrm{meq} / \mathrm{L})\end{array}$ & $\begin{array}{l}\text { COD } \\
(\mathrm{ppm})\end{array}$ \\
\hline \multirow[t]{2}{*}{ Q2 } & Newsprint & $\begin{array}{c}\text { Raw } \\
\text { waters }\end{array}$ & 7.4 & 1.90 & 3.66 & 897 & 0.61 & - \\
\hline & & $\begin{array}{c}\text { DCM } \\
\text { fraction }\end{array}$ & 7.4 & 1.95 & - & 107 & 0.61 & 1716 \\
\hline \multirow[t]{2}{*}{ Q3 } & Newsprint & $\begin{array}{c}\text { Raw } \\
\text { waters }\end{array}$ & 7.6 & 2.95 & 4.90 & 1420 & 0.57 & - \\
\hline & & $\begin{array}{c}\text { DCM } \\
\text { fraction }\end{array}$ & 7.6 & 2.96 & - & 95 & 0.57 & 1648 \\
\hline Q4 & LWC & $\begin{array}{c}\text { Raw } \\
\text { waters }\end{array}$ & 8.5 & 3.60 & 8.66 & 12200 & 0.56 & 2967 \\
\hline
\end{tabular}

\subsubsection{Tests of single chemical systems on process water of newsprint production}

Following the methodology proposed for the selection of the most efficient chemical, the efficiency of PANS-PA was studied at different dosages (50-350 mg/L). Results for the removal of turbidity, cationic demand and COD in the clarified waters are summarized in Figure 6. Turbidity reductions, referred to blank values, ranged from 13 to $86 \%$, depending on the dosage of PANS-PA used. Intermediate dosages such as $200 \mathrm{mg} / \mathrm{L}$ demonstrated to be good enough for obtaining good clarification levels (72\% removal of turbidity; residual turbidity $108 \mathrm{NTU}$ ). The turbidity of the DCM fraction of the waters was slightly reduced with dosage increase, and a maximum of a $20 \%$ reduction has been observed (data not shown). There is a linear correlation between the dosage of PANS-PA and the cationic demand of the clarified waters, a maximum of $70 \%$ reduction being observed at the highest dosage. Intermediate dosages of PANS-PA, e.g. $200 \mathrm{mg} / \mathrm{L}$, reduced $46 \%$ of the cationic demand. Reduction of COD is also linearly related to the PANS-PA dosage, but the reduction is only of $7 \%$ from maximum dosage. Intermediate dosages of PANS-PA such as $200 \mathrm{mg} / \mathrm{L}$, could reduce the COD by around 3-4\%. 


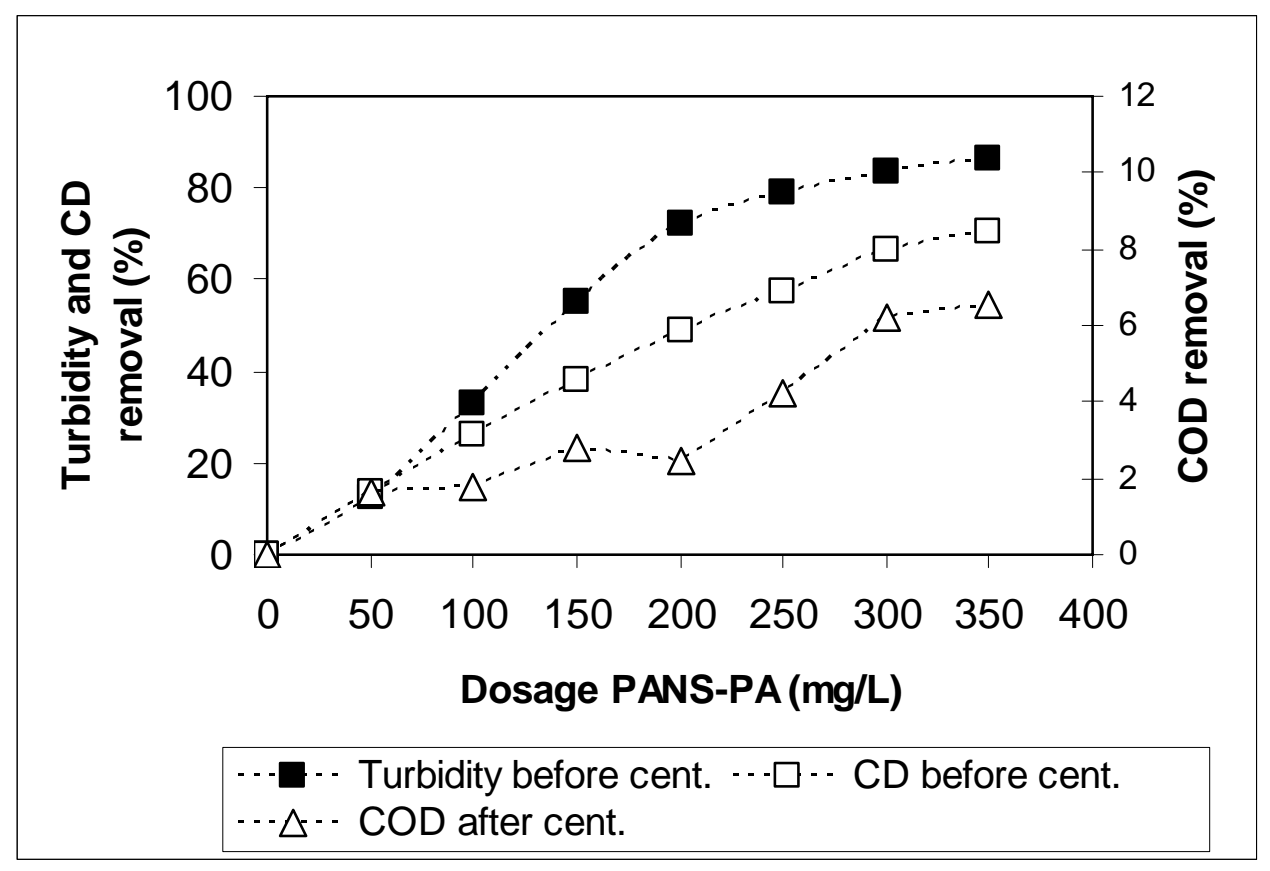

Figure 6. Removal of the turbidity and COD as a function of PANS-PA dosage.

Total, suspended and dissolved solids were also measured in these samples. The solids in the inlet DAF waters were mainly in the dissolved fraction. For a total of $3.66 \mathrm{~g} / \mathrm{L}$ of total solids, $1.15 \mathrm{~g} / \mathrm{L}$ were suspended solids (31\%) and $2.51 \mathrm{~g} / \mathrm{L}$ were dissolved solids (69\%). DAF, without adding any chemicals, reduced the total solids from $3.66 \mathrm{~g} / \mathrm{L}$ to $2.47 \mathrm{~g} / \mathrm{L}$, removing mostly suspended solids. The addition of PANS-PA reduced the total solids content to $2.0 \mathrm{~g} / \mathrm{L}$ at the highest dosage, removing some extra suspended solids $(0.17 \mathrm{~g} / \mathrm{L})$ and dissolved solids $(0.30 \mathrm{~g} / \mathrm{L})$. PANS-PA did not affect the conductivity of the clarified waters, indicating neither dissolved salts are removed nor does PANS-PA increase the conductivity.

\subsubsection{Tests of dual chemical systems on process waters of newsprint production}

A complementary study has been carried out to evaluate the synergistic effect of using PANS-PA in combination with a flocculant and to compare the new product with the one used at the mill. Process waters used in this study were from newsprint production (Q3 waters). PANS-PA and the coagulant COAG were tested alone at four concentrations (100, 150, 200 and $250 \mathrm{mg} / \mathrm{L}$ ) and in dual systems at two concentrations (100 and $200 \mathrm{mg} / \mathrm{L}$ ) with two different levels of flocculant (FLOC) (2 and $4 \mathrm{mg} / \mathrm{L}$ ). The flocculant used in these studies (FLOC) is that used at the mill for cleaning the process waters in DAFs. This product is used alone when newsprint is produced and it is used in combination with the coagulant COAG when LWC paper is produced, due to the higher contamination load of the waters in these conditions. 
Results obtained for single and dual systems are summarized in Figure 7. In single systems, COAG seems to be a little more efficient than PANS-PA, both for turbidity and cationic demand removal. In the range of dosages tested, the only effect that is enhanced when higher dosages of coagulant are used is the reduction in cationic demand. Neither the turbidity, the COD nor the TOC varied significantly when the dosage of coagulant increased. A dosage of $100-150 \mathrm{mg} / \mathrm{L}$ seems to be adequate for the treatment of this type of waters, although optimal dosages determined at lab-scale could be reduced significantly at industrial scale because of the poorer hydrodynamics of the DAF lab-cell. As was expected, the use of FLOC on its own significantly reduces the turbidity of the samples, but can not reduce the cationic demand, the COD or the TOC.

In dual systems, the efficiency of COAG and PANS-PA were practially the same. The slightly better behaviour of COAG used alone (mostly referred to turbidity removal) is compensated by a major synergetic effect between PANS-PA and FLOC. This means that the use of FLOC in combination with PANS-PA is recommended for the field trial. The additional cost of the flocculant could be compensated by the difference of price between PANS-PA and COAG, especially according to the low dosages of flocculant which are necessary.

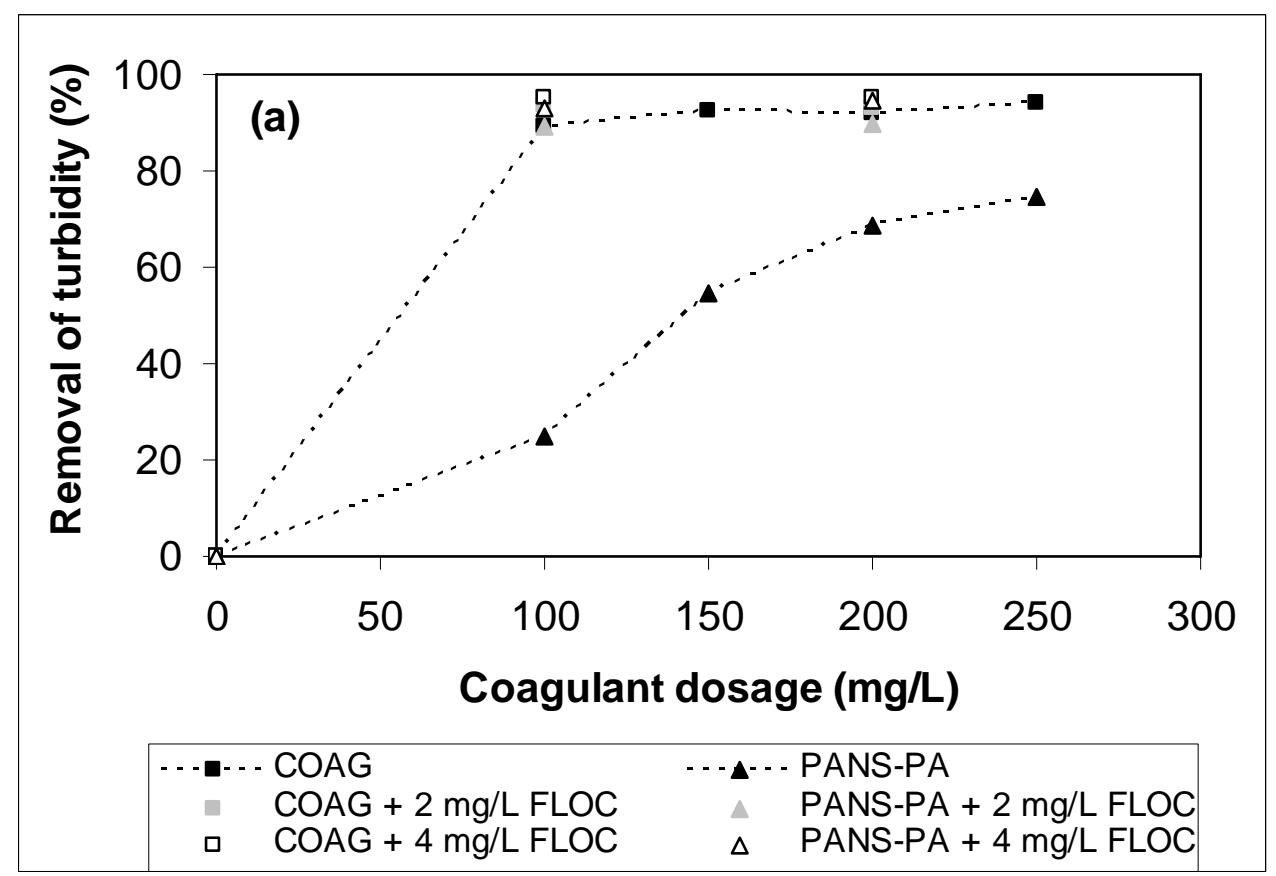



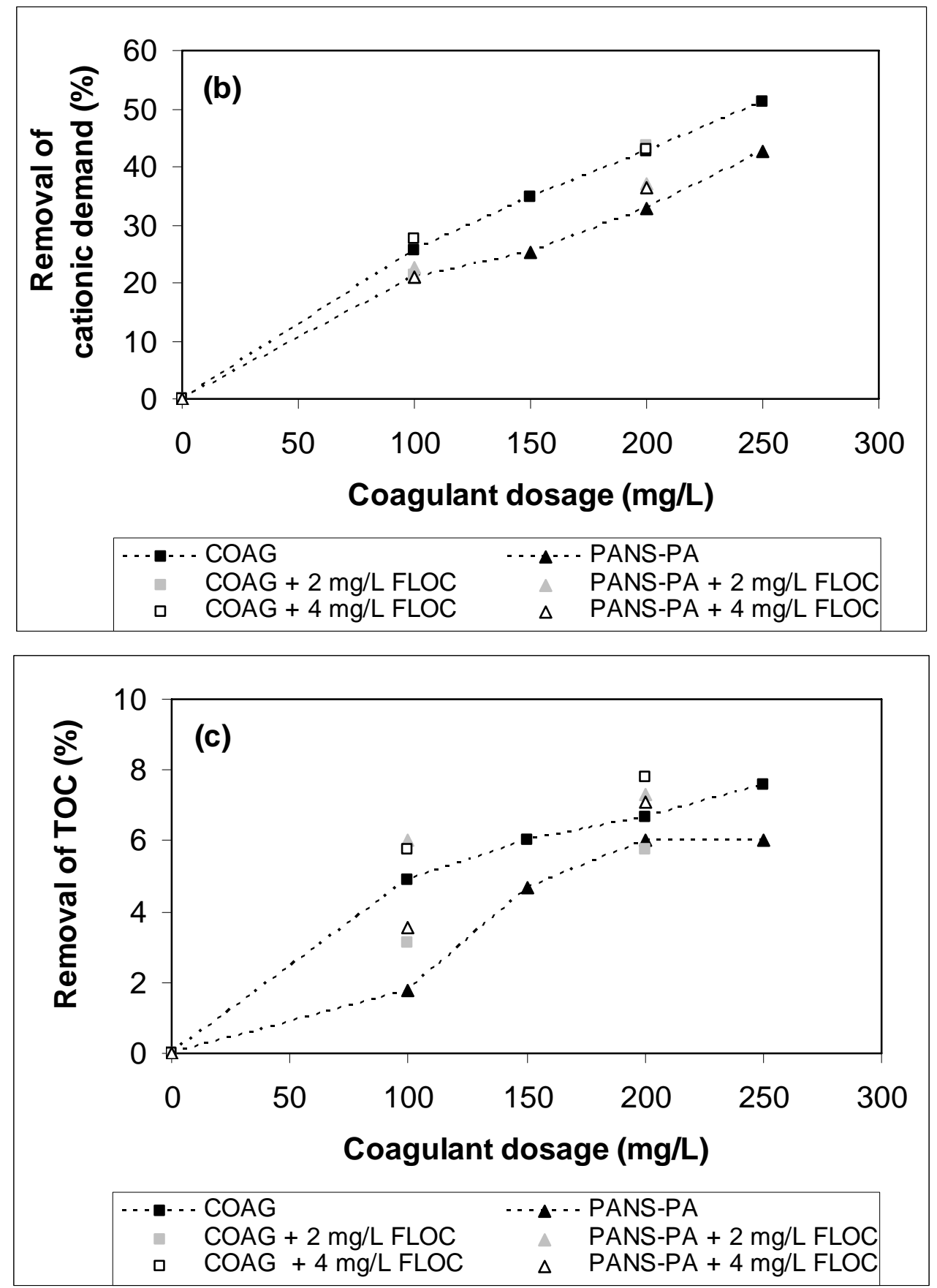

Figure 7. Comparison of PANS-PA and reference coagulant (COAG): a) Turbidity removal; b) Cationic demand removal; c) TOC removal.

\subsubsection{Tests on process water of LWC production}

The contamination load of the water when this product is manufactured is much higher than in the case of newsprint. Figure 8 shows the turbidity and cationic demand of clarified waters after the treatment of LWC waters with PANS-PA, PACS-PA and COAG. The maximum reduction of turbidity is around $97 \%$, referred to as the blank. This removal is obtained with 300-350 mg/L of COAG and $400 \mathrm{mg} / \mathrm{L}$ of PANS-PA and PACS-PA. The efficiency of 
COAG is slightly higher than PANS-PA or PACS-PA but, as it was observed for newsprint production, the addition of flocculant could significantly improve the PANS-PA or PACS-PA results. Cationic demand of the samples treated with PANS-PA, PACS-PA and COAG are very similar. A reduction of about $50 \%$ is achieved with dosages of $350-400 \mathrm{mg} / \mathrm{L}$. Results from COD are very similar for the different treatments (not shown) with reductions always between $4-6 \%$ with respect to the blank. They were measured after filtration through a 0.45 $\mu \mathrm{m}$ syringe filter. Similar results are obtained with $350 \mathrm{mg} / \mathrm{L}$ of COAG or $400 \mathrm{mg} / \mathrm{L}$ of PANS-PA and PACS-PA.
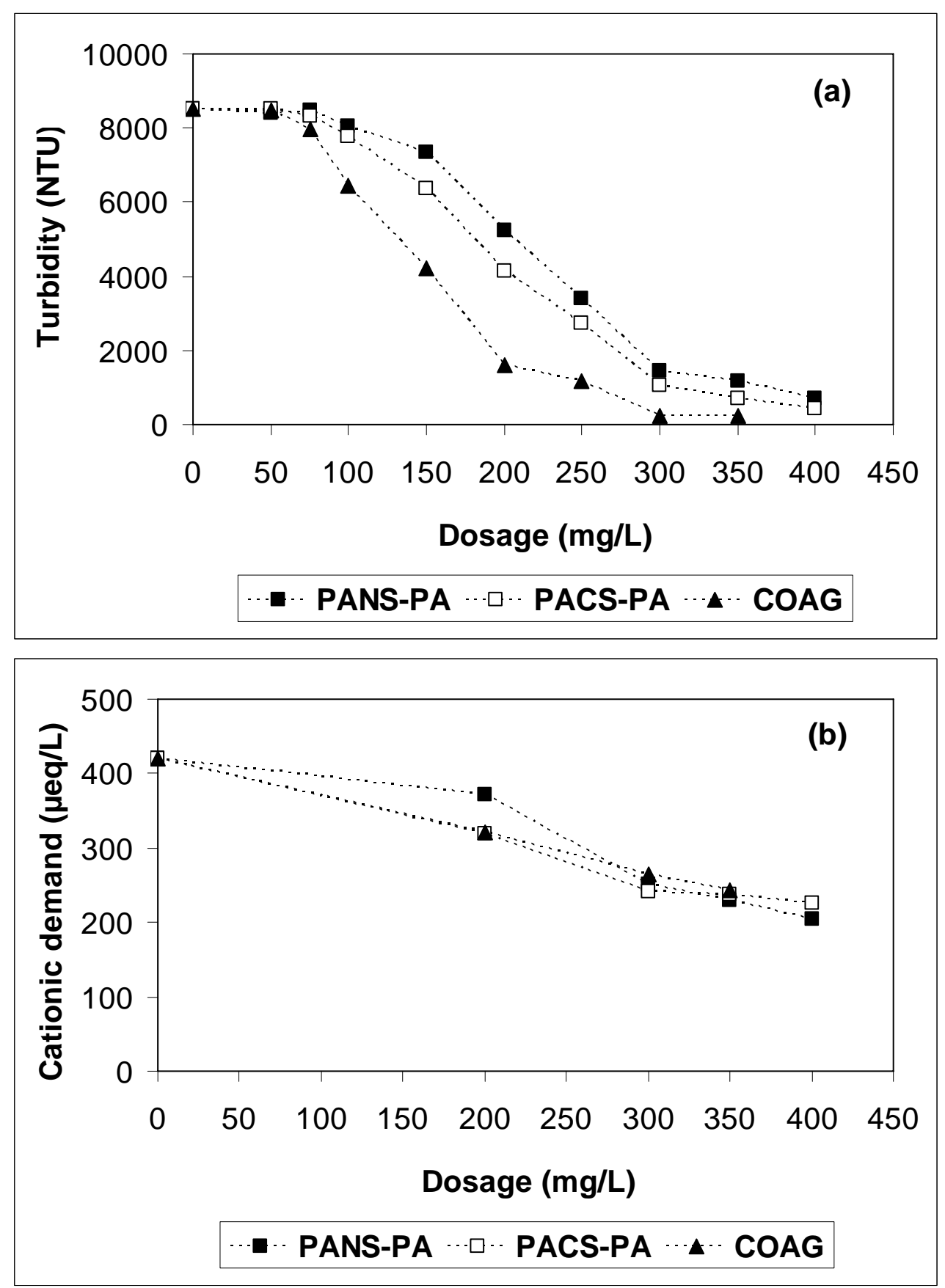

Figure 8. Comparative efficiency of the PANS-PA, PACS-PA and reference coagulant (COAG): a) Turbidity removal; b) Cationic demand removal. 
As a mean value, to obtain similar results in turbidity, cationic demand or COD, a dosage of COAG of $300-350 \mathrm{mg} / \mathrm{L}$ is necessary versus around $400 \mathrm{mg} / \mathrm{L}$ for PANS-PA and PACS-PA. However, the viability of the substitution of COAG will depend on the final price of PANSPA. Dosages as high as 350-400 mg/L are necessary, at lab scale, to obtain high levels of cleanness for LWC paper production due to the high contamination load of the waters.

\section{CONCLUSIONS}

Different combinations of 3 polyaluminium salts and 3 cationic polyelectrolytes have been tested at lab-scale for taking advantage of the synergic between organic and inorganic coagulants in the removal of contaminants by DAF in waters from newsprint and LWC production. The polyamine modification of the polyaluminium salts, PACS-PA and PANSPA, greatly improved the efficiency of the reference aluminium salt. Polyamine modifications (at 700-800 mg/L dosages at lab-scale) improved contaminants removal by DAF: more than $90 \%$ of turbidity before centrifugation and 50\% after centrifugation, and nearly $90 \%$ of the cationic demand (before and after centrifugation) and around 15\% of the COD of the centrifuged samples. PANS-PA was selected as the most efficient product due to the slightly better efficiency compared to PACS-PA. Before deciding to carry out a field trial with PANS$\mathrm{PA}$, some preliminary tests were carried out for gaining more knowledge about the efficiency of this product under different conditions and for defining the initial dosage to be used in the field trial. Due to the promising results obtained, a field trial was recommended to assess the long-term benefits of its use in DAF systems. The preliminary tests allow us to recommend the use of PANS-PA in combination with a flocculant.

\section{ACKNOWLEDGMENTS}

The authors would like to thank the financial support from the European Union through the Project "Reduction of detrimental substances in papermaking" (QLK5-CT-2001-00749) and from the Madrid Community through the program PROLIPAPEL (S-0505/AMB/0100). The collaboration of Holmen Paper Madrid and Sachtleben Chemie GmbH are also acknowledged.

\section{REFERENCES}

(1) Blanco, A.; Negro, C.; Monte, C.; Fuente, E.; Tijero, J. The challenges of sustainable papermaking. Environ. Sci. Technol. 2004, 38, 414.

(2) Abou-Elela, S.I.; Nasr, F.A.; Ibrahim, H.S.; Badr, N.M.; Askalany, A.R.M. Pollution prevention pays off in a board paper mill. J. Clean. Prod. 2008, 16, 330.

(3) Asghar, M.N.; Khan, S.; Mushtaq, S. Management of treated pulp and paper mill effluent to achieve zero discharge. J. Environ. Manage. 2008, 88, 1285. 
(4) Bobu, E.; Ciolacu, F.; Anghel, N. Prevention of colloidal material accumulation in short circulation of paper machine. Wochenbl. Papierfabr. 2002, 9, 576.

(5) Miranda, R.; Blanco, A.; Negro, C. Accumulation of dissolved and colloidal material in papermaking - Application to simulation. Chem. Eng. J. 2008, doi:10.1016/j.cej.2008.09.014.

(6) Vendries, E.; Pfromm, P.H. Influence of closure on the white water dissolved solids and the physical properties of recycled linerboard. Tappi J. 1998, 81, 206.

(7) Xu, Y.; Deng, Y. The buildup of dissolved solids in closed white water systems. Tappi J. 2004, 3, 17.

(8) Belosinschi, D.; Bobu, E. Process water of papermaking: model building and characterization. Environ. Eng. Manag. J. 2007, 6, 261.

(9) Bourgogne, G.; Laine, J. E. A review of the effects of reduced water consumption on the wet end of the paper machine and the quality of water. Pap. Puu 2001, 83, 190.

(10) Blanco, A.; Miranda, R.; Negro, C.; Garcia-Suarez, C.; Garcia-Prol, M.; Sanchez, A. Full characterization of stickies in a newsprint mill: the need for a complementary approach. Tappi J. 2007, 6, 19.

(11) Miranda, R.; Balea, A.; Sanchez de la Blanca, E.; Carrillo, I.; Blanco, A. Identification of recalcitrant stickies and their sources in newsprint production. Ind. Eng. Chem. Res. 2008, 47, 6239.

(12) Lee, H.K.; Ham, C.H.; Lee, S.G. Influence of papermaking system closure on paper properties. Tappi J. 2006, 5, 27.

(13) Gilbert, C.D.; Hsieh, J.S.; Xu, Y.; Deng, Y. Effects of white-water closure on the physical properties of linerboard. Tappi J. 2000, 83, 68.

(14) Zhang, X.; Beatson, R.P.; Cai, Y.J.; Saddler, J.N. Accumulation of specific dissolved and colloidal substances during white water recycling affects paper properties. J. Pulp Pap. Sci. 1999, 25, 206.

(15) Mittal, A.H.; Iribarne, J.; Rajan, K.G.; Chatterjee, S.G. Buildup of dissolved solids in a paperboard mill with water closure. Prog. Pap. Recycl. 2006, 15, 19.

(16) Miranda, R.; Blanco, A.; Negro, C.; Tijero, J. Stickies removal in a deinking line of a newsprint mill: efficiency of the different process stages. Cellul. Chem. Technol. 2006, 40, 775.

(17) Brun, J.; Delagoutte, T.; Carre, B. Origins and effects of dissolved and colloidal materials. Prog. Pap. Recycl. 2007, 17, 12.

(18) Faul, A. Quality aspects of recovered paper for deinking. Prog. Pap. Recycl. 2005, 15, 6. 
(19) Fairbank, M.; Keenan, D.; Peters, H.; Prein, M.; Schwarzbach, A.; Wells, L. Effect of recovered paper quality and deinking process parameters on dirt levels in newsprint. Pulp Pap. Can. 2006, 107, 64.

(20) Ackermann, C.; Gottsching, L.; Pakarinen, H. Papermaking potential of recycled fiber. In: Göttsching, L. and Pakarinen, H. (eds). Papermaking Science and Technology, Book 7, Recycled Fiber and Deinking; Fapet Oy: Jyväskylä (Finland), 2000, 359-439.

(21) Sarja, T. Measurement, nature and removal of stickies in deinked pulp. Thesis dissertation, June 2007. University of Oulu (Finland).

(22) Ben, Y.; Dorris, G. M.; Page, N. Characterization of dissolved air flotation rejects. Pulp Pap. Can. 2004, 105, 28.

(23) Meixner, H.; Auhorn, W. J., Gercke, M. Tailor-made cationic polymers for fixing detrimental substances of primary and secondary origin. Papier 1998, 52, 36.

(24) Ben, Y.; Dorris, G.; Hill, G.; Allen, J. Contaminant removal from deinking process water, Part I: mill benchmarking. Pulp Pap. Can. 2003, 104, 42.

(25) Roring, A.; Wackerberg, E. Characterization of deinking white water - influence on flotation and bleaching efficiency. Pulp Pap. Can. 1997, 98, 17.

(26) Putz, H. K. Stickies in recycled fiber pulp. In: Göttsching, L. and Pakarinen, H. (eds). Papermaking Science and Technology, Book 7, Recycled Fiber and Deinking; Fapet Oy: Jyväskylä (Finland), 2000, 441-498.

(27) Dunham, A. J.; Tubergen, K. R.; Govoni, S. T.; Alfano, J. C. The effects of dissolved and colloidal substances on flocculation of mechanical pulps. J. Pulp Pap. Sci. 2000, 26, 95.

(28) Basta, A. H.; Zhan, H.; He, B.; Wang, X.; Zao, G. Cleaning efficiency of process water in newsprint mill. Prog. Pap. Recycl. 2004, 13, 13.

(29) Negro, C.; Blanco, A.; Saarimaa, V.; Tijero, J. Optimization of pitch removal by dissolved air flotation in a Eucalyptus kraft mill. Sep. Sci. Technol. 2005, 40, 1129.

(30) Saarimaa, V.; Sundberg, A.; Holmbom, B. H.; Blanco, A.; Negro, C.; Fuente, E. Purification of peroxide-bleached TMP water by dissolved air flotation. Tappi J. 2006, 5, 15.

(31) Saarimaa, V.; Sundberg, A.; Holmbom, B.; Blanco, A.; Fuente, E.; Negro, C. Monitoring of dissolved air flotation by focused beam reflectance measurement. Ind. Eng. Chem. Res. 2006, 45, 7256.

(32) Pelzer, R.; Kenzel, U. Polyacrylamides (PAM) for process water treatment in the production of mechanical printing papers. Wochenbl. Papierfabr. 2006, 134, 1320.

(33) Miranda, R.; Blanco, A.; de la Fuente, E.; Negro, C. Separation of contaminants from deinking process water by dissolved air flotation: effect of flocculant charge density. Sep. Sci. Technol. 2008, 43, 3732. 
(34) Pernitsky, D. J.; Edzwald, J. K. Selection of alum and polyaluminum coagulants: principles and applications. J. Water Supply Res. Technol. AQUA 2006, 55, 121.

(35) Mehta, A.; Sain, M.; Ni, Y.; Morneau, D. Chemical additive optimization program: short-cycle clarification of deinking mill alkaline-water loop. Pulp Pap. Can. 2004, 105, 43.

(36) Thurley, D.; Niemczyk, B.; Turner, G. Use of dissolved air flotation to clean process water. Appita J. 1997, 50, 109.

(37) Sain, M.; Li, H.; Morneau, D. Chemical-pretreatment of deinking mill waste waster prior to DAF. Prog. Pap. Recycl. 2002, 12, 13.

(38) Sarja, T.; Zabihian, M.; Kourunen, J.; Niinimäki. New method for measuring potential secondary stickies in deinked pulp filtrates. Water Sci. Technol. 2004, 50, 207.

(39) Huang, L.; Xiao, H.; Ni, Y. Cationic-modified microporous zeolite/anionic polymer system for simultaneous removal of dissolved and colloidal substances from wastewater. Sep. Purif. Technol. 2006, 49, 264.

(40) Gao, B.Y.; Yue, Q.Y.; Wang, B.J.; Chu, Y.B. Poly-aluminium-silicate-chloride (PASiC) - a new type of composite inorganic polymer coagulant. Colloids Surf., A 2003, 229, 121.

(41) de Nardi, I. R.; Fuzi, T. P.; Del Nery, V. Performance evaluation and operating strategies of disolved-air flotation system treating poultry slaughterhouse wastewater. Resour. Conserv. Recycl. 2008, 52, 533.

(42) Blanco, A.; de la Fuente, E.; Negro, C.; Monte, M. C.; Tijero, J. Focused beam reflectance measurement as a tool to measure flocculation. Tappi J. 2002, 1, 14.

(43) Blanco, A.; Fuente, E.; Negro, C.; Tijero, J. Flocculation monitoring: focused beam reflectance measurement as a measurement tool. Can. J. Chem. Eng. 2002, 80, 734.

(44) Blanco, A.; Negro, C.; Fuente, E.; Tijero, J. Effect of shearing forces and flocculant overdose on filler flocculation mechanisms and floc properties. Ind. Eng. Chem. Res. 2005, 44, 9105.

(45) Standard Methods for the Examination of Water and Wastewater; APHA-AWWAWPCF: Washington, United States, $17^{\text {th }}$ edition, 1989. 